\title{
Potentiostatic threshold potentials of stainless steels
}

\author{
Martin Mehlich ${ }^{1, *}$, Hans Hoffmeister ${ }^{1}$, Thomas Böllinghaus ${ }^{2}$, and Christoph Münster ${ }^{1}$ \\ ${ }^{1}$ Institute for Failure Analysis and Failure Prevention (ISSV) e.V., c/o Helmut-Schmidt-University /University of the Federal Armed \\ Forces, 22043 Hamburg, Germany \\ ${ }^{2}$ Federal Institute for Materials Research and Testing (BAM), 12205 Berlin, Germany
}

\begin{abstract}
Potentiodynamic measurements are used to determine key potentials to classify certain corrosion properties. The material selection for components (e.g. shafts) in corrosive environments is widely based upon these potentiodynamic measurements. Criticism for using these potentials for component design has been expressed in literature. Potentiostatic measurements are known to represent the long term corrosive impact experienced by components in a more realistic manner but are prone to scatter. Therefore a statistical approach called staircase method was adapted to the given electrochemical problem.

With using this staircase method, a reliable value for the median potential (threshold potential) can be determined. This potential defines the threshold between anodic dissolution and cathodic protection. For the first time, this newly defined potentiostatic threshold potential is offering a validated median potential value for corrosion prediction in a given corrosion system based on potentiostatic measurements. Threshold potentials for the stainless steel grades 1.4057 and 1.4542 were investigated in aerated electrolytes at $25^{\circ} \mathrm{C}$ with different chloride ion concentrations.
\end{abstract}

\section{Introduction}

Potentiodynamic measurements are used to determine key potentials such as corrosion potential, pitting potential and repassivation potential. These potentials are usually determined by the resulting current exceeding a defined threshold during a potentiodynamic measurement. The material selection for components (e.g. shafts) in corrosive environments is widely based upon these dynamically measured potentials.

In recent years, failure cases have been described for components designed according to these standards. Criticism for using these potentials (e.g. the repassivation potential) for component design has been expressed repeatedly in literature $[1,2,3]$. One major point of criticism is that the long term corrosion prediction is based on a short term dynamically measured potential value which is barely taking the kinetics of chemical reactions into account.

Because the chemical reactions can come close to the state of the chemical equilibrium during potentiostatic measurements, some authors suggest that potentiostatic measurements are more suitable for predicting the long term corrosion resistance of stainless steels [1]. But potentiostatic measurements are prone to scatter. As a consequence several identical measurements are necessary to gain reliable results.

To minimize the number of experiments necessary for gaining reliable results, a statistical approach was chosen. This approach is called up-and-down method and is also known as staircase method [4].

\section{Experimental approach}

\subsection{Staircase method}

The outcome of each potentiostatic test is a current that is dependent from the applied potential and the point of time the current is measured at. This measured current can either be of anodic or cathodic nature. Because of the scatter, the individual potentiostatic tests were carried out in a statistically optimized staircase sequence. This staircase sequence is widely used for fatigue testing and was adapted to the given electrochemical problem for the first time.

The sequence of operation is given in figure 1. A reliable value for the median potential can be determined, defining the threshold between anodic dissolution and cathodic protection. Therefore the identified median potential value is subsequently defined as threshold potential $\left(\mathrm{E}_{\mathrm{T}}\right)$.

Before initiating the sequence, a start potential and the potential step $(\delta)$ between the levels have to be defined. Beginning with the chosen start potential, the potential values of each consecutive experiment are determined by equation 1 and 2 . These equations state that, in case the resulting current is anodic, the potential

\footnotetext{
* Corresponding author: martin.mehlich@hsu-hh.de
} 
of the following measurement is lowered by one step while for cathodic results the potential value is increased by one step.

Valid experiments are all experiments that were executed on lower potential levels than the highest potential level occupied with more than one experiment. A sequence consists out of a minimum of 10 valid experiments. For reliable statistical results no more than five potential levels and no less than three potential levels shall be occupied. The potential value of the lowest occupied potential level is defined as $E_{j 0}$. Counting from level $\mathrm{E}_{\mathrm{j} 0}=0$, the potential levels are numbered with an increasing index. The number of experiments conducted on each level is defined as $f_{j}$.

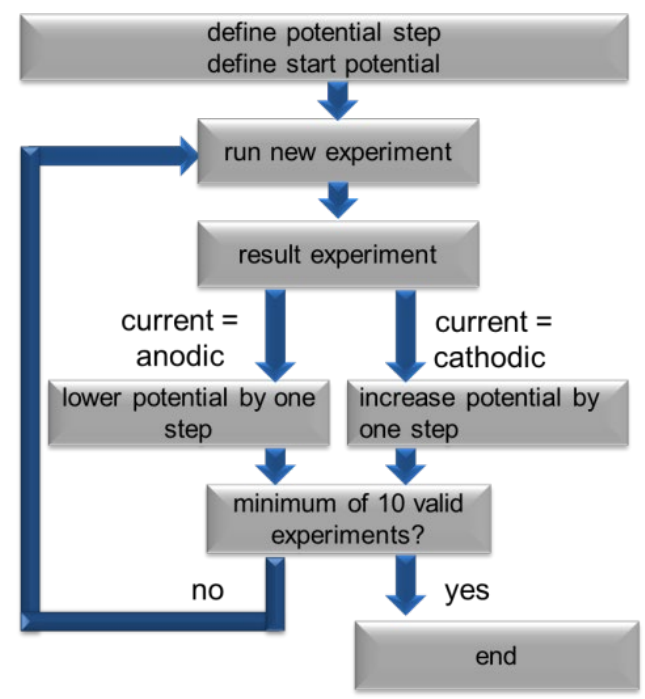

Fig. 1. Sequence of operation diagram of the staircase method

$$
\begin{aligned}
& \text { if result of experiment } \mathrm{n}-1 \triangleq \text { cathodic current } \\
& \qquad E_{\text {level }_{n}}=E_{\text {level }_{n-1}}+\delta \\
& \text { if result of experiment } \mathrm{n}-1 \triangleq \text { anodic current } \\
& E_{\text {level }_{n}}=E_{\text {level }_{n-1}}-\delta
\end{aligned}
$$

In figure 2 the test sequence and the calculation principals are visualized while the numerical approach is described by the equations 3 to 5 . For the calculation of the median threshold potential value the auxiliary variables $f_{F}$ and $f_{A}$ are needed (see equation 3 and 4 ). The variable $f_{F}$ is defined as the sum of all valid experiments. The number of valid experiments on each level is multiplied with the index number of the level to form a product; the sum of these products is defined as variable $\mathrm{f}_{\mathrm{A}}$ (see equation 4 ).

For the calculation of the median value one fictional data point is added to the sequence at the potential level determined by the last experiment executed (according to equation 2). This data point marks the end of the sequence. The threshold potential can then be calculated according to equation 5 .

$$
f_{F}=\sum f_{j}
$$

$$
\begin{gathered}
f_{A}=\sum j * f_{j} \\
E_{T}=E_{j 0}+\delta * \frac{f_{A}}{f_{F}}
\end{gathered}
$$

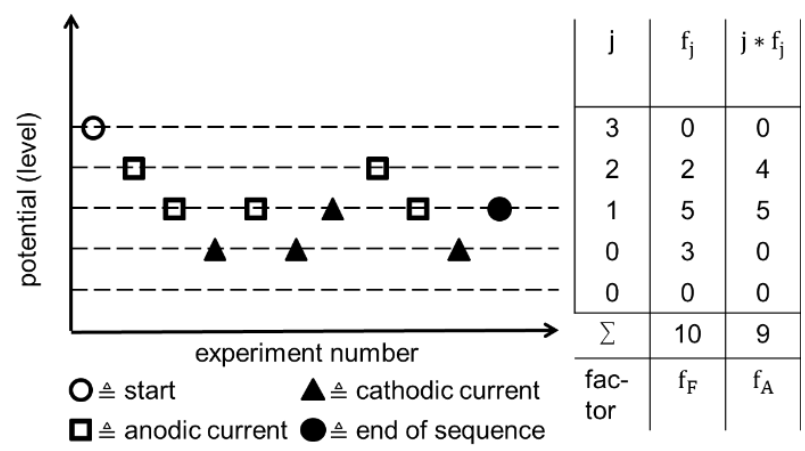

Fig. 2. Schematic experiment sequence and calculation visualisation.

\subsection{Specimen preparation}

A test specimen of stainless steel was embedded in epoxy resin leaving a flat surface area of $1 \mathrm{~cm}^{2}$ available for testing. The finishing surface polish was carried out with P800 sandpaper. Using this preparation setup, a maximum surface roughness of $\mathrm{R}_{\mathrm{a}}=1.7 \mu \mathrm{m}, \mathrm{R}_{\mathrm{z}}=18 \mu \mathrm{m}$ and $\mathrm{R}_{\mathrm{V}}=16 \mu \mathrm{m}$ was achieved.

\subsection{Stainless steels}

The martensitic steel 1.4057 and the precipitation hardening steel 1.4542 were investigated; the tested steel 1.4542 had a primarily martensitic microstructure. Both steels were analyzed with an optical emission spectrometer to identify the chemical compositions ( table 1).

Table 1. Chemical compositions of the stainless steels 1.4057 and 1.4542 (amounts given in weight-\%, Fe -balance).

\begin{tabular}{|c|c|c|c|c|c|}
\hline & $\mathrm{C}$ & $\mathrm{Si}$ & $\mathrm{Mn}$ & $\mathrm{P}$ & $\mathrm{S}$ \\
\hline 1.4542 & 0.04 & 0.38 & 0.71 & 0.017 & 0.002 \\
\hline 1.4057 & 0.17 & 0.40 & 0.56 & 0.019 & 0.001 \\
\hline & $\mathrm{Cr}$ & $\mathrm{Mo}$ & $\mathrm{Ni}$ & $\mathrm{Cu}$ & $\mathrm{Nb}$ \\
\hline 1.4542 & 15.8 & 0.14 & 4.8 & 3.4 & 0.28 \\
\hline 1.4057 & 15.9 & 0.15 & 1.73 & - & - \\
\hline
\end{tabular}

\subsection{Bulk solution}

The bulk solution was created by dissolving sodium chloride or magnesium chloride in deionized water. Chloride concentrations ranged from $0.02 \mathrm{~mol} / \mathrm{l}$ up to the point of saturation (salts) at $25^{\circ} \mathrm{C}$. A constant $\mathrm{pH}$ value of 4 was achieved by adding acetic acid to the solution. The aerated solution was maintained at a temperature of $25^{\circ} \mathrm{C}$ throughout the experiment. 


\subsection{Experimental procedure}

The series of independent potentiostatic tests were conducted in a standardized cell comparable to the corrosion test cell described in the ASTM standard [5]. A three electrode setup with an $\mathrm{Ag} / \mathrm{AgCl}$ reference electrode was used. Each test was performed with a new specimen and a new bulk solution. A time span of 50,000 seconds for each experiment was selected according to Mehlich [1]

\section{Results}

Conducting a sequence of independent potentiostatic tests by using the staircase method led to the findings exemplarily given in figure 3 . The diagram shows the conducted sequences of consecutive potentiostatic tests in accordance with the sequence of operation. The calculated threshold potentials are plotted in the diagram.

In figure 4 the results of 11 sequences are given. Each data point was generated by a sequence of at least 10 independent potentiostatic tests. Table 2 shows the numerical results of the investigated threshold potentials. These results are leading to the equation 6 , describing the threshold potential in dependency of the chloride ion concentration. The term $\mathrm{E}_{\mathrm{T} 1}$ describes the threshold potential measured for the electrolyte-steel combination at $1 \mathrm{~mol} / \mathrm{l}$ chloride ion concentration.

Logarithmic correlations between chloride ion concentration and threshold potential were found for all investigated electrolyte-steel combinations.

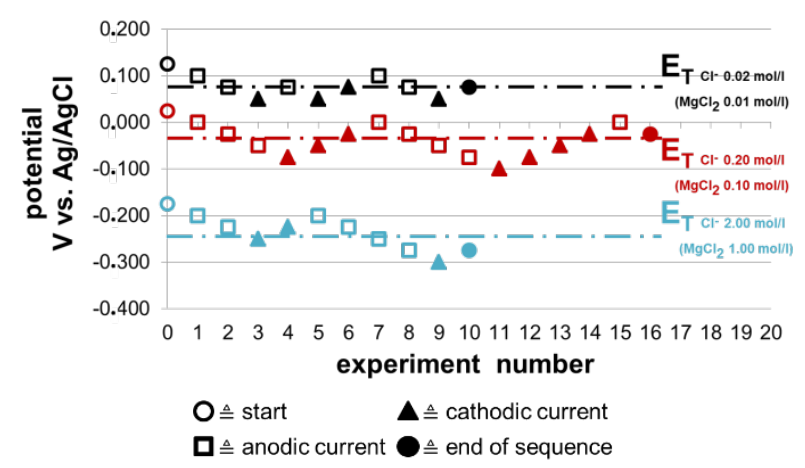

Fig. 3. Results for the steel 1.4542 with marked threshold potentials for electrolytes with different chloride ion concentrations. Black: $\mathrm{MgCl}_{2} 0.01 \mathrm{~mol} / 1\left(\mathrm{Cl}^{-} \triangleq 0.02 \mathrm{~mol} / \mathrm{l}\right)$, red: $\mathrm{MgCl}_{2} \quad 0.10 \mathrm{~mol} / 1 \quad\left(\mathrm{Cl}^{-} \triangleq 0.20 \mathrm{~mol} / \mathrm{l}\right)$, blue: $\mathrm{MgCl}_{2}$ $1.00 \mathrm{~mol} / 1\left(\mathrm{Cl}^{-} \triangleq 2.00 \mathrm{~mol} / \mathrm{l}\right)$ aerated solution $\mathrm{pH} 4$ at $25^{\circ} \mathrm{C}$.

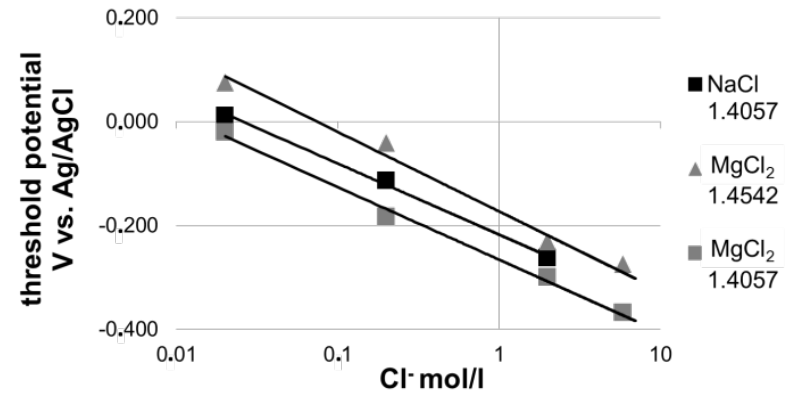

Fig. 4. Dependency of the threshold potential $\mathrm{E}_{\mathrm{T}}$ for different electrolyte-steel combinations (salt: $\mathrm{NaCl}$, black; $\mathrm{MgCl}_{2}$, grey; steel: 1.4057 , square; 1.4542 , triangle).

Table 2. Threshold potentials for different electrolyte-steel combinations.

\begin{tabular}{|r|c|c|c|}
\hline $\mathrm{mol} / \mathrm{l} \mathrm{Cl}^{-}$ & $\begin{array}{c}\mathrm{NaCl} / 1.4057 \\
\mathrm{~V} \text { vs. } \\
\mathrm{Ag} / \mathrm{AgCl}\end{array}$ & $\begin{array}{c}\mathrm{MgCl}_{2} / 1.4542 \\
\mathrm{~V} \text { vs. } \\
\mathrm{Ag} / \mathrm{AgCl}\end{array}$ & $\begin{array}{c}\mathrm{MgCl}_{2} / 1.4057 \\
\mathrm{~V} \text { vs. } \\
\mathrm{Ag} / \mathrm{AgCl}\end{array}$ \\
\hline 0.02 & 0.008 & 0.073 & -0.018 \\
\hline 0.20 & -0.113 & -0.042 & -0.180 \\
\hline 2.00 & -0.263 & -0.243 & -0.318 \\
\hline saturation & - & -0.269 & $-0,346$ \\
\hline
\end{tabular}

$$
\mathrm{E}_{\mathrm{T}\left(\mathrm{n} \mathrm{Cl}^{-}\left[\frac{\mathrm{mol}}{\mathrm{l}}\right]\right)} \cong 0.06 \ln \left(\mathrm{n} \mathrm{Cl}^{-}\left[\frac{\mathrm{mol}}{\mathrm{l}}\right]\right)+\mathrm{E}_{\mathrm{T} 1}
$$

\section{Discussion}

Dependencies similar to equation 6 were found by Dong et al. [6] and Suzuki et al. [7] for dynamically measured potentials. Both groups of authors were studying the influence of the chloride ion concentration on the pitting potential respectively the critical potential for pit growth. Dong et al. [6] found the correlation described by equation 7 for the steel 1.4462. Suzuki et al. [7] found the correlation described by equation 8 for $316 \mathrm{~L}$.

$$
\begin{gathered}
E_{L}=A-b \log [\mathrm{NaCl}] \\
E=0.044 \log \left[\mathrm{Cl}^{-}\right]-0.268 \mathrm{~V}(\mathrm{SCE})
\end{gathered}
$$

Both correlations show logarithmic dependencies for the analyzed potentials in respect to the chloride ion concentration. Anderko et al. [3] also found and calculated this logarithmic dependency for the activity of chloride ion concentrations (greater $0.01 \mathrm{~mol} / \mathrm{l}$ ) for the repassivation potentials of different alloys.

To conclude, the major dynamically measured key potentials (e. g. pitting potential, repassivation potential) show a logarithmic dependency on the chloride ion concentration. The newly defined threshold potential does also show the same correlation for the investigated chloride ion concentrations. In contrast to the former mentioned dynamically gained potentials, the newly defined threshold potential is based upon a statistic approach using potentiostatic measurements, allowing a reliable long term prediction for the resulting current. 
By using the introduced staircase sequence it is possible to investigate the anodic/cathodic threshold for any given electrolyte-surface combination of metals. Therefore it is possible to describe realistic corrosion systems instead of just ranking materials with the standardized dynamically measured potential values.

\section{References}

1. M. Mehlich Schwellenpotentiale martensitischer Chromstähle (2019)

2. B. Wilde, E. Williams, Electrochim. Acta 16, 11, 1971-1985 (1971)

3 A. Anderko, N. Sridhar, D. Dunn, Corros. Sci. 46, 7, 1583-1612 (2004)

4. M. Hück, Mat.-wiss. u. Werkstofftech. 14, 12, 406-417 (1983)

5. ASTM International Volume 03.02 (2003)

6. C. Dong, H. Luo, K. Xiao, T. Sun, Q. Liu, X. Li, J. Wuhan Univ. Technol.-Mat. Sci. Edit. 26, 4, 641647 (2011)

7. T. Suzuki, Y. Kitamura, Corrosion 28 1, 1-6 (1972) 